${ }^{13}$ Cf. C. G. Hempel and Paul Oppenheim, "The Logic of Explanation," Philosophy of Science, vol. 15 (1948). While this definition is adequate for many purposes, it is oversimplified in some ways. Theorem 1 depends on the form of this definition, but our general approach is consistent with any explicatum of 'explain.'

${ }^{14}$ Cf. footnote 6.

${ }^{15}$ For example, $\mathrm{T}_{2}^{\prime}$ may state that $\mathrm{T}_{2}$ holds under specified conditions.

${ }^{18} \mathrm{Cf}$. H. Feigl's contribution to the symposium on operationism in the Psychological Review, vol. 52, no. 5 (September 1945).

\title{
Further Remarks on Definition and Analysis
}

\author{
by IRVING M. COPI \\ UNIVERSITY OF MICHIGAN
}

A NUMBER of acute criticisms have been directed against some of the views presented in my essay "Analytical Philosophy and Analytical Propositions" (this journal, December 1953). I welcome them as providing stimulation and opportunity for penetrating more deeply into the issues involved.

The central notion in my discussion is that of a theoretical definition. A theoretical definition of a term is intended to formulate a theoretically adequate characterization of the objects to which that term applies. One gives a theoretical definition of a term to attach to the term, as intension, that property which in the context of a given theory is most useful for understanding or predicting the behavior of those entities which comprise the (usual) extension of that term.

In his "Definitions in Analytical Philosophy" (this journal, April 1954) Michael Scriven has correctly observed that a given theoretical definition is compatible with a wide range of different theories (p. 38). Several different theories may have the same vocabulary (of terms or of concepts), or they may have parts of their vocabularies in common. And that common area of vocabulary may be all that is used in the definition of a given term. With respect to a theoretical definition, therefore, Mr. Scriven is right in saying that it is incorrect to talk of the theory which underlies it. I am therefore happy to accept his suggestion that my remarks on this point should be modified. I would say now that accepting a theoretical definition involves accepting as correct some theory in whose terminology the definition is formulated.

It should be clear, however, that a theoretical definition may be disputed for either (or both) of two different reasons. One may dispute a theoretical definition because of disagreement with the theory one believes to under- 
lie it. Or one may object to the definition because it assigns to the definiendum a meaning which differs too greatly from its prior meaning, thus making it denote more or fewer objects than it did in some previous usage. It is this second reason to which Mr. Scriven correctly calls attention when he writes that some disputes about theoretical definitions "depend on prior meaning of the term, hence imply criticisms of it as a lexical definition" (p. 39). But clearly it may be decided that some change in a term's extension is not too great a price to pay for the gain in theoretical insight (and/or predictive power) achieved by changing the intension of that term. For example, chemists have continually redefined the term "acid": earlier, as a substance which in water solution yields hydrogen ion; later, as any substance which can give up or transfer protons to something else; more broadly, as a substance whose molecule can accept a pair of electrons to form a coordinate bond. And it is no objection to any of these definitions that the intensions specified by them are different from each other, or from the one applied by housewives and mechanics in their use of the term. Of course it might be objected that the chemist's definition makes water an acid whereas no mechanic or housewife would ever use the term "acid" to denote water. Yet the advantage achieved in explaining "acid" in terms of ionization (or atomic) theory is sufficient to outweigh this objection, and water is referred to in chemistry textbooks as a weak acid (as on p. 279 of Smith's College Chemistry, Sixth Edition). This departure from the previous meaning of the term "acid," extensional as well as intensional, is entirely legitimate. The legitimacy of any such proposed departure is, of course, open to debate, since some departures are justified whereas others may not be.

Despite what Mr. Scriven has written (point 4 on p. 37, and point 5 on p. 38) I cannot agree that all definitions are analytic. Since the lexical definitions found in dictionaries are empirical reports of word usage, it is clear that at least one kind of definition (and the paradigm, at that) is not analytic. Stipulative definitions can be regarded either as proposals to use the definiendum in a specified way ("Let us use the term 'war' to mean ...") or as predictions that it will be used in a specified way ("In this discussion I shall use the term 'war' to mean ..."). On the first interpretation the stipulative definition is a command or invitation and not a proposition at all, hence not an analytical proposition. And on the second interpretation it is a prediction which may be false, for many writers inadvertently depart from the usage they themselves had announced; on this interpretation a stipulative definition is clearly a proposition, but just as clearly it is not an analytical one. I suspect that Mr. Scriven is using the term "definition" in some sense which I have not managed to understand. 
When I turn to Mr. Carmichael's discussion "Professor Copi Concerning Analysis" (this journal, October 1954) I am inclined to think that the disagreement between us is more apparent than real. I am in complete agreement with the first statement in his discussion. Analysis surely requires analytical means, that is, a body of terms already understood, or concepts already grasped, by whose means or in terms of which other terms or concepts may be analyzed, explicated, or defined. Let us call such a collection of terms or concepts an "analytical base." Thus classes and relations were the analytical base in terms of which the Frege-Russell analysis of number was carried out, sense data terms (plus logical ones) are the analytical base in terms of which phenomenalists have sought to analyze physical objects, and atoms of elements and their valence bonds are the analytical base used by chemists in their analyses of compounds.

Certain formal criteria, such as consistency and noncircularity, can be appealed to in criticizing any analysis whatever. But a proposed analysis can also be criticized for inadequacies in its analytical base. The terms or concepts ingredient in a particular analytical base may themselves be challenged, that is, regarded as problematic. The notion of class has been so challenged, and has been given various different analyses, some in terms of set theory, others in terms of extensions of functions. The notion of sense datum has also been challenged. And the problematic character of atoms has been (part of) the stimulation for physicists to construct more elaborate atomic theories involving more and different sub-atomic particles in their analytical bases.

At this point let us refer to the dilemma which Mr. Carmichael poses very clearly on page 74: "If we are going to analyze, we must have the wherewithal, consisting, surely, of an apparatus of ideas; now these are to be either primitive or not; if primitive, they are prohibited; if not primitive, they cannot be expected to yield more than a superficial analysis." I have already indicated my agreement with the first clause in accepting the notion of an analytical base. But the notion of a "primitive" idea is surely relative to a context-as negation is primitive in the context of the Russell-Whitehead logic, but not primitive in the context of Nicod's system. In the context of any given analysis, the terms in the analytical base are of course primitive, and I did not intend to prohibit them, although my words unfortunately suggested to Mr. Carmichael that I did. But when the terms in that analytical base are challenged, that new problem determines a new context, and in that new context-if the demand for their analysis is met-they are not primitive but must be analyzed in terms of some new analytical base whose elements are primitive in the new context.

The preceding remarks may seem to imply the start of an infinite re- 
gression, and some philosophers have sought to avoid the threat of such regression by suggesting that there is some absolutely primitive level of rock bottom certainty beyond which analysis cannot penetrate. Russell's search for "hard data" (Scientific Method in Philosophy, pp. 70ff) seems to reflect this concern. Such suggestions strike me as being more dangerous than the threatened regression. First, because they seek to impose limits on the process of free inquiry, and, second, because to the extent that they simply assume their primitives to be unconditionally primitive, they must be recognized as varieties of dogmatism. Like the notion of preventive war, these suggestions seem to be more deadly than what they are intended to prevent. For there is, after all, only a threat of a regression. Its construction is contingent on the interests of philosophical analysts. Only if the terms primitive in a given analysis are challenged does a new context of inquiry arise. And in truth there is no end to philosophizing; no concepts need be regarded as sacrosanct.

There is still a third alternative. We need not choose between becoming involved in a regression, on the one hand, or positing some absolutely primitive terms or concepts, on the other. A basis for explanation, that is, an analytical base, need not be either actually analyzed or held to be unanalyzable. There is a different method for appraising the worth of a proposed analytical base. It is adequate to the extent to which it permits the formulation of an adequate theory for explaining the various concepts to be analyzed in its terms.

This criterion is the one used in appraising the adequacy of scientific hypotheses or theories. To the extent that a scientific theory is successful in accounting for the facts, that is, in organizing and systematizing the data in its field, to that extent it is regarded as correct or adequate. I suggest that the same general criteria apply to philosophical theories that apply to scientific ones. I would stress the continuity of scientific and philosophical inquiry, rather than their differences, although their differences are not to be denied.

Let me summarize the view on which I hope I am in agreement with Mr. Carmichael. First, every analysis requires the use of some analytical base, which is a set of concepts that are used but not themselves analyzed in that context. Second, those latter concepts may be themselves analyzed (in a different context), although that further analysis need not always be performed, and is not to be regarded as a necessary condition for, or a presupposition of, the initial analyses. Third, in defending the adequacy of a proposed analysis, one must be prepared to defend the adequacy of the analytical base used therein. To do so, one may either (1) go on to analyze the concepts used in that proposed analysis, or (2) maintain that those concepts are primitive and unanalyzable in some absolute sense, 
or (3) urge their adequacy on the grounds that their use permits the formulation of a theory which accounts for the facts to be explained, and is corroborated by its utility in analyzing still further facts, or still additional new terms or concepts. And in this connection alternative (3) seems least objectionable, in that it avoids the regression hinted at, though not strictly implied by (1), and in that it avoids the dogmatism of alternative (2).

The foregoing remarks are in agreement with Mr. Scriven's assertion (p. 37) that 'The production of 'definitions' is at most a small part of 'the end results of philosophical analysis'." For the main task of the philosopher is to set up and work out the analytical base in whose terms definitions are to be formulated.

Apart from its (perhaps deliberate) circularity, Mr. Scriven's remark (p. 39) that "the business of philosophical analysis is to appraise the correctness or adequacy of philosophical analyses" is acceptable to me, though I should want to draw rather different conclusions from it than he does. It seems obvious to me that one task involved in appraising the adequacy of a proposed analysis is an examination of its analytical base. And a suffcient reason for rejecting that analytical base would be that its adoption would (somehow) preclude adequate analyses of other but equally important notions. Attention must surely be given to ensuring the mutual consistency of our analyses of different notions. Hence no single analysis can be accepted as finally satisfactory until other analyses have been accomplished and seen to be consistent with that one. Mr. Scriven seems to ignore this problem, writing (p. 39) "And it is precisely insofar as philosophical analysis has abandoned the idea of an all-embracing theory of being' that it does not share 'the traditional goal of speculative, systematic, synoptic philosophy'." I am not sure what Mr. Scriven means by his phrase "all-embracing theory of being." If he means an analytical base in whose terms analyses can be given for all other notions that philosophers deem worthy of analysis, then if they abandon that, philosophers run the risk of contradicting themselves in their analyses of different notions.

This point has been extremely well put by D. J. O'Connor in a recent essay in Analysis (vol. 14, no. 5, April 1954, p. 110): "we can clarify the situation in our immediate vicinity by sweeping the difficulties out to the periphery. But sooner or later, these peripheral problems will become central in another context and we shall then find that our piecemeal methods of philosophizing have shifted our difficulties from one place to another instead of solving them. And that is, I suppose, one justification of the philosophical system-building that is at present so unfashionable." In my opinion Mr. O'Connor's "one justification" of the traditional goal of speculative, systematic, synoptic philosophy is ample justification for it. 
That it is unfashionable at present is but one among many manifestations of the anxiety and "loss of nerve" characteristic of the period through which Western culture is now passing. ${ }^{1}$

Received August 6, 1955

\title{
NOTE
}

${ }^{1}$ One critic has reported diffculty in finding in Ayer's Language, Truth and Logic any assertion that the proper task of philosophy is to provide definitions. I attributed that view to Ayer on the basis of his remarks on pages 49,59,62,64-65, and 68 of the first edition of that work (repeated on pages 50-51, 55-56, 57, 58-59, and 60 of the second edition).

\section{On a Certain Use of Quotation Marks}

\author{
by G. P. HENDERSON
}

UNIVERSITY OF ST. ANDREWS

WE BEGIN with the familiar:

(1) Seneca wrote that man is a rational animal

Consider the suggestion that an analysis of (1) (of an elementary kind) is provided by

(2) Seneca wrote "Man is a rational animal"

The automatic objection to this is that Seneca wrote no such thing, just as Copernicus did not assert "The planetary orbits are circles." 1 Hence,

(3) Seneca did not write "Man is a rational animal" is true.

L. J. Cohen and A. C. Lloyd have recently drawn attention to a distinction in the use of quotation marks which, I suggest, could be used so as to 'correct' (2), with the minimum of rewriting, and bring it into consistency with (3).2 They say that there is a "tacit convention . . . by which sentences can be quoted as being the sentences which . . . would be ... uttered in the relevant contexts if the language there used ... were . . . the same as that of the main text." 3 To mark the observance of this convention (which we may call Convention A) they propose that single quotation marks be employed. Such quoted sentences stand in contrast with quoted sentences which must be regarded as ipsissima verba, and hence are not translatable. For them, the use of double quotation marks is proposed.

According to this convention, not only are (1) and (3) compatible, but (3) would also be compatible with 